\title{
REKAYASA PERANGKAT LUNAK INFORMASI KEMISKINAN
}

\author{
Ahmad Haidar Mirza' ${ }^{1)}$ (Usman Ependi ${ }^{2)}$, Febriyanti Panjaitan ${ }^{3)}$ \\ Fakultas Ilmu Komputer, Universitas Bina Darma \\ J1, A. Yani No. 3, Palembang - Sumatera Selatan, 30264 \\ Telp : (0711) 515581, Fax : (0711) 515581 \\ E-mail : haidarmirza@mail.binadarma.ac.id ${ }^{1)}$
}

\begin{abstract}
Abstrak
Dalam rangka mengimplementasikan berbagai program penanggulangan kemiskinan, informasi mengenai siapa yang miskin dan dimana mereka berada menjadi sangat penting dan akan menjadi modal dasar dalam targeting rumah tangga miskin. Dengan kata lain, agar program penanggulangan kemiskinan berhasil dan tepat sasaran, maka ketersediaan data kemiskinan yang terpercaya merupakan suatu keharusan. Di Indonesia sendiri, sumber data mengenai kemiskinan telah tersedia di berbagai sumber. Namun demikian, sumber yang resmi digunakan oleh pemerintah adalah data kemiskinan yang bersumber dari Badan Pusat Statistik (BPS). Data kemiskinan yang bersumber dari BPS sering menjadi dasar dalam implementasi program penanggulangan kemiskinan oleh pemerintah. Berdasarkan penelitian yang telah dilakukan sebelumnya, proses penentuan pola data kemiskinan dengan menggunakan metode KDD (Knowlerge Discovery in Database) dengan memakai data PPLS dari Badan Pusat Statistik menghasilkan tujuh pola informasi. Ketujuh pola informasi tersebut dihasilkan berdasarkan hasil analisis data dan requirement pada Badan Perencanaan Pembangunan Daerah (BAPPEDA) terhadap data kemiskinan. Ketujuh pola informasi tersebut merupakan hasil dari pengclusteran / pengelompokan data kemiskinan berdasarkan wilayah dan tingkat kemiskinan berdasarkan indikator kemiskinan. Proses rekayasa perangkat lunak informasi kemiskinan dibangun dengan menggunakan metode Rapid Application Deveopment (RAD) untuk memenuhi kebutuhan pemerintah akan informasi data kemiskinan.
\end{abstract}

Kata kunci: Kemiskinan, Perangkat Lunak, RAD

\section{PENDAHULUAN}

Masalah kemiskinan merupakan salah satu persoalan mendasar yang menjadi pusat perhatian pemerintah. Salah satu aspek penting untuk mendukung Strategi Penanggulangan Kemiskinan adalah tersedianya data kemiskinan yang akurat dan tepat sasaran. Data kemiskinan berdasarkan PPLS tidak terlepas dari pengaruh garis kemiskinan dan cara memandang kemiskinan itu sendiri yang disetiap wilayah di Indonesia ini berbeda-beda. Kriteria kemiskinan dan cara pandang yang berbeda-beda akan menimbulkan penafsiran yang berbeda-beda pula tentang jumah penduduk miskin,kriteria penduduk miskin dan tingkat penanganan terhadap persoalan kemiskinan. Data kemiskinan yang teranalisis juga akan dapat digunakan untuk mengevaluasi kebijakan pemerintah terhadap masalah kemiskinan, membandingkan kemiskinan antar waktu dan daerah, serta menentukan target penduduk miskin dengan tujuan untuk memperbaiki kondisi mereka melalui sebuah program penanganan kemiskinan.

Dalam rangka mengimplementasikan berbagai program penanggulangan kemiskinan, informasi mengenai siapa yang miskin dan dimana mereka berada menjadi sangat penting dan akan menjadi modal dasar dalam targeting rumah tangga miskin. Dengan kata lain, agar program penanggulangan kemiskinan berhasil dan tepat sasaran, maka ketersediaan data kemiskinan yang terpercaya merupakan suatu keharusan. Berdasarkan Peraturan Menteri Dalam Negeri Nomor 42 Tahun 2010 Tentang Tim Koordinasi Penanggulangan Kemiskinan Provinsi Dan Kabupaten/Kota, pasal 1 menyebutkan Program penanggulangan kemiskinan adalah kegiatan yang dilakukan oleh pemerintah, pemerintah daerah, dunia usaha, serta masyarakat untuk meningkatkan kesejahteraan masyarakat miskin melalui bantuan sosial, pemberdayaan 
masyarakat, pemberdayaan usaha ekonomi mikro dan kecil, serta program lain dalam rangka meningkatkan kegiatan ekonomi. Di Indonesia sendiri, sumber data mengenai kemiskinan telah tersedia di berbagai sumber. Namun demikian, sumber yang resmi digunakan oleh pemerintah adalah data kemiskinan yang bersumber dari Badan Pusat Statistik (BPS). Data kemiskinan yang bersumber dari BPS sering menjadi dasar dalam implementasi program penanggulangan kemiskinan oleh pemerintah.

Salah satu langkah adalah dengan mengolah data kemiskinan dalam sebuah proses KDD (Knowlerge Discovery in Database) untuk membentuk data mining kemiskinan. Data mining adalah kombinasi secara logis antara pengetahuan data, dan analisa statistik yang dikembangkan dalam pengetahuan bisnis atau suatu proses yang menggunakan teknik statistik, matematika, kecerdasan buatan, tiruan dan machine-learning untuk mengekstraksi dan mengidentifikasi informasi yang bermanfaat bagi pengetahuan yang terkait dari berbagai database besar [4].

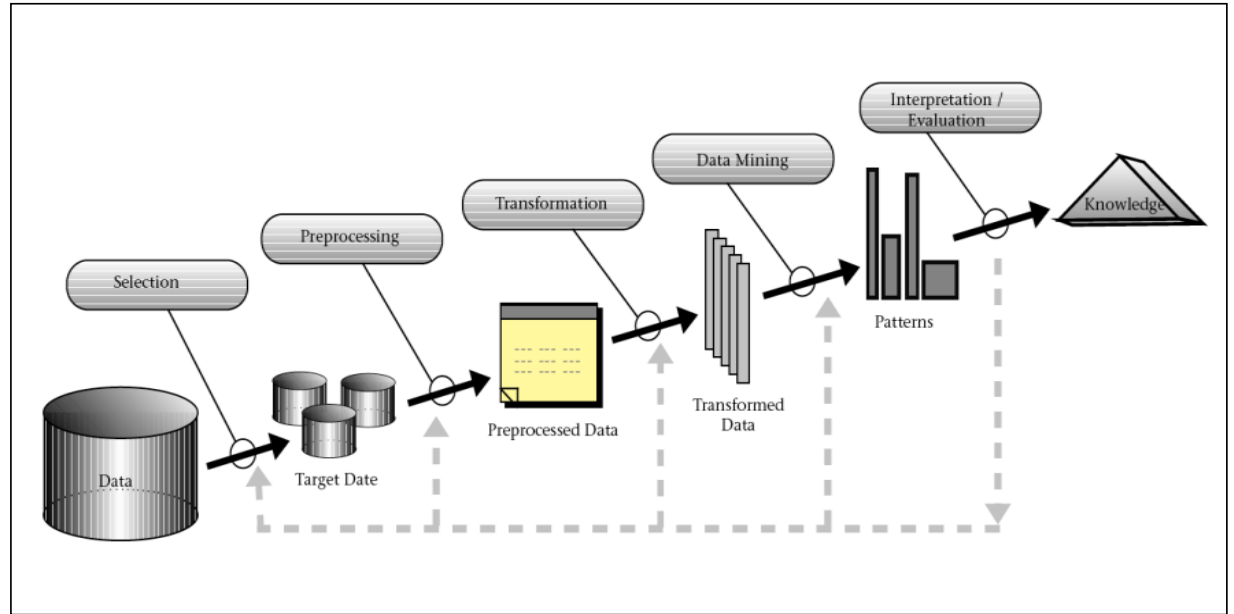

Gambar 1. Knowlage Discovery in Database(KDD)

Gambar di atas menjelaskan tahapan $K D D$ untuk melakuan ektrasi informasi dalam database kemiskinan sehingga didapat sebuah pola informasi berbasis pengetahuan yang dapat digunakan dalam pengambilan kebijakan yang tetap sasaran untuk menentukan langkah didalam penanggulangan kemiskinan.Tahapan KDD meliputi tahapan Selection, Preprocesing, Transformation, Data Mining dan Interpretation/Evalution. Tahapan tersebut menghasilkan proses penentuan pola data kemiskinan berdasarkan data PPLS dari Badan Pusat Statistik mengelompokan data tujuh model data yang memetakan tujuh pola informasi. Ketujuh pola informasi tersebut dihasilkan berdasarkan hasil analisis data requirement pada Badan Perencanaan Pembangunan Daerah (BAPPEDA) terhadap data kemiskinan. Ketujuh pola informasi tersebut merupakan hasil dari peng-cluster-an / pengelompokan data kemiskinan berdasarkan wilayah, tingkat kemiskinan dan indikator kemiskinan. Hasil dari ketujuh pola informasi ini akan ditransformasikan kedalam bentuk aplikasi berbasis web yang akan dibangun pada tahun ke dua. Aplikasi ini diharapkan dapat digunakan oleh pemerintah dalam memahami pola data kemiskinan sehingga dapat membantu memberikan informasi yang berguna bagi pemerintah dalam mengambil kebijakan dalam perencanan pembangunan yang akan berdampak dalam bagi pengurangan angka kemiskinan.

\section{METODE PENELITIAN}

Metode penelitian yang digunakan adalah metode deskriptif kualitatid yang disesuaikan dengan metode pengembangan perangkat lunak. Adapun metode yang digunakan adalah rapid application development (RAD). Metode RAD digunakan 
untuk mengembangakan atau mengimplementasikan hasil dari model data mining yang telah didapat. Metode RAD memilki tahapan sebagai berikut [3].

\section{Bussiness modeling}

Pada tahapan business process, pekerjaan yang dilakukan adalah analisis proses bisnis dari pengelolahan data penduduk miskin pada Bappeda OKI dan Banyuasin, informasi apasaja yang dikelolah, sumber informasi yang didapat dan pengguna dari perangkat lunak penduduk misikin.

\section{Data modeling}

Pada tahapan ini pekerjaan yang dilakukan adalah mendefinisikan dari fase business modeling disaring ke dalam serangkaian objek data yang dibutuhkan untuk menopang bisnis tersebut. Pemodelan data yang dibuat berdasarkan hasil requirement (kebutuhan) perangkat lunak data mining kemiskinan yang akan dibangun.

\section{Process modeling}

Pada tahapan process modeling pekerjaan yang dilakukan adalah membuat alur proses dari perangkat lunak peduduk miskin. Alur proses yang dibuat tersebut mencakup menambah, memodifikasi, menghapus, atau mendapatkan kembali sebuah objek data

\section{Application generation}

Tahapan application generation pekerjaan yang dilakukan adalah melakukan pengkodean atau implementasi dari process modeling dan data modeling. Pengkodean tersebut dapat dilakukan dengan cara menggununakan kembali kode-kode yang telah ada sebelumnya (reused).

\section{Testing and turnover}

Pada tahapan testing, pekerjaan yang dilakukan adalah melakukan pengujian perangkat lunak penduduk miskin yang telah dibuat. Pengujian tersebut dilakukan pada perangkat lunak yang memiliki komponen baru. Pengujian tersebut dilakukan secara menyeluruh mulai dari komponen data mining sampai dengan komponen perangkat lunak penduduk miskin.

\section{HASIL \& PEMBAHASAN}

Penelitian yang dilakukan mengikuti langkah-langkah dalam metode Rapid Application Development (RAD).

\subsection{Bussiness Modeling}

Tahapan bussiness modeling merupakan suatu teknik pemodelan yang digunakan untuk menggambar model sebuah bisnis. Untuk melakukan business modeling maka dilakukan survey sistem dengan mengunjungi objek yang akan menggunakan sistem. Survey sistem bertujuan untuk mengetahui kondisi eksisting objek sebelum dilakukan analis sistem yang akan mengidentifikasi masalah dan memberikan solusi terhadap masalah. Jika sudah ada sistem yang berjalan sebelumnya maka perlu dilakukan pengumpulan data dan informasi yang dihasilkan dari sistem yang ada. Pengumpulan laporan (report), cetakan (print-out), dsb baik yang sudah ada maupun yang diharapkan untuk ada pada sistem yang baru. Observasi dan interview terhadap orang-orang yang terlibat dalam sistem juga mungkin perlu dilakukan. Apabila sistem yang akan dikembangkan benar-benar baru (belum ada sistem informasi sebelumnya) maka pada 
tahapan ini pengembang bisa lebih menekankan kepada studi kelayakan dan definisi sistem. Berikut ini hal-hal yang harus dipenuhi oleh perangkat lunak kemiskinan yang akan dibangun :

1. Penyebaran informasi penduduk miskin untuk setiap wilayah.

2. Tingkat pendidikan penduduk dan tingkat kemiskinan per wilayah.

3. Usia penduduk dan tingkat kemiskinan per wilayah.

4. Kondisi tempat tinggal dan tingkat kemiskinan per wilayah.

5. Cara perolehan air minum dan penerangan dengan tingkat kemiskinan per wilayah.

6. Pekerjaan dengan tingkat kemiskinan per wilayah.

7. Jenis kelamin dengan tingkat kemiskinan per wilayah.

Aplikasi ini dikembangkan dalam 2 (dua) modul utama, yaitu modul aplikasi BackOffice dan FrontOffice. Modul aplikasi BackOffice merupakan fungsi utama dari perangkat lunak kemiskinan dimana data kemiskinan maupun hasilnya diolah dan ditampilkan. Modul ini memiliki 3 (tiga) modul utama, yaitu Bantuan, Entry Data Keluarga Miskin dan Laporan. Sedangkan aplikasi FrontOffice merupakan modul pelaporan yang dapat digunakan oleh instansi pemerintah atau pihak terkait yang membutuhkan data kemiskinan untuk melaksanakan program kegiatan yang berhubungan dengan penanggulangan kemiskinan.

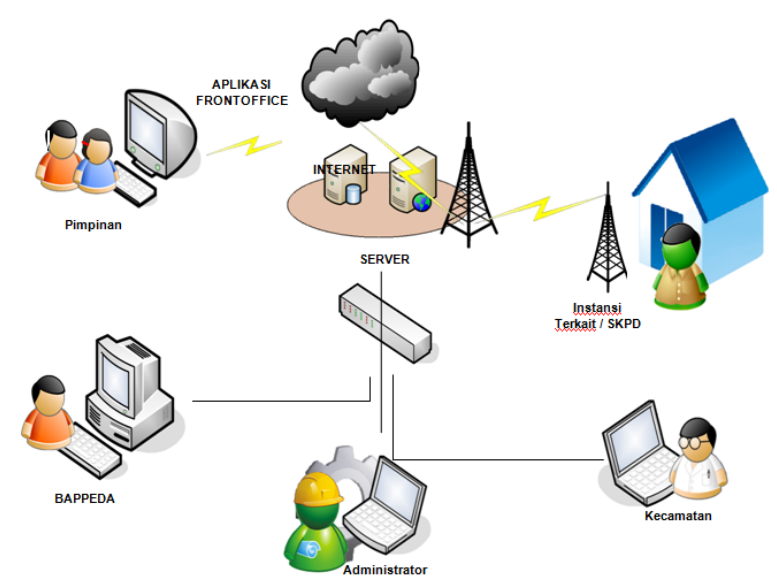

Gambar 2. Arsitektur Aplikasi

Arsitektur model perangkat lunak kemiskinan dibangun berbasis web sehoingga mempermudah pengaksesan informasi secara global oleh setiap stacholder terkait (gambar 2). Fitur/fasilitas perangkat lunak kemiskian dapat dijabarkan sebagai berikut :

1. Data Master
a. Data Indikator
b. Data Bantuan
c. Data Kecamatan
d. Data Desa

2. Data Indikator Kemiskinan

a. Pencocokan data KK-BPS Antarmuka Pencocokan Data Kepala Keluarga dalam dbKemiskinan dengan Kepala Keluarga dalam database kependudukan.

b. Pemeliharaan Indikator Kemiskinan Antarmuka Pemeliharaan data Indikator Kemiskinan 
3. Pengolahan Kemiskinan

a. Ekstrak data penerima bantuan Kemiskinan sesuai kriteria BPS Antarmuka Penentuan Penerima Bantuan Kemiskinan Sesuai Kriteria, Antarmuka Daftar Calon Penerima Bantuan Kemiskinan.

b. Ekstrak data penerima bantuan Kemiskinan sesuai indikator pilihan Antarmuka Pemilihan Indikator untuk Menentukan Penerima Bantuan Kemiskinan, Antarmuka Daftar Calon Penerima Bantuan Kemiskinan.

c. Update Data Penduduk Miskin.

4. Informasi / Laporan Data Kemiskinan

a. Penyebaran informasi penduduk miskin untuk setiap wilayah.

b. Tingkat pendidikan penduduk dan tingkat kemiskinan per wilayah.

c. Usia penduduk dan tingkat kemiskinan per wilayah.

d. Kondisi tempat tinggal dan tingkat kemiskinan per wilayah.

e. Cara perolehan air minum dan penerangan dengan tingkat kemiskinan per wilayah.

f. Pekerjaan dengan tingkat kemiskinan per wilayah.

g. Jenis kelamin dengan tingkat kemiskinan per wilayah.

Dari hasil survey dan analis yang dilakukan, maka dapat digambarkan bussiness modeling dalam sebuah diagram UML (Unifed Modeling Language). Unified Modeling Language (UML) merupakan satu kumpulan konvensi pemodelan yang digunakan untuk menentukan atau menggambarkan sebuah sistem software yang terkait dengan objek [5]. UML dapat digunakan untuk membuat model dalam software development ataupun membuat permodelan bisnis (bussiness modeling). UML menyediakan sepuluh model proses untuk menggambarkan model proses, diataranya . Use Case Diagram digunakan untuk memodelkan bisnis proses berdasarkan perspektif pengguna sistem. Use case diagram terdiri atas diagram untuk use case dan actor. Actor merepresentasikan orang yang akan mengoperasikan atau orang yang berinteraksi dengan sistem aplikasi. Berikut Use case diagram untuk bussiness modeling perangkat lunak kemiskinan yang akan dibangun. 


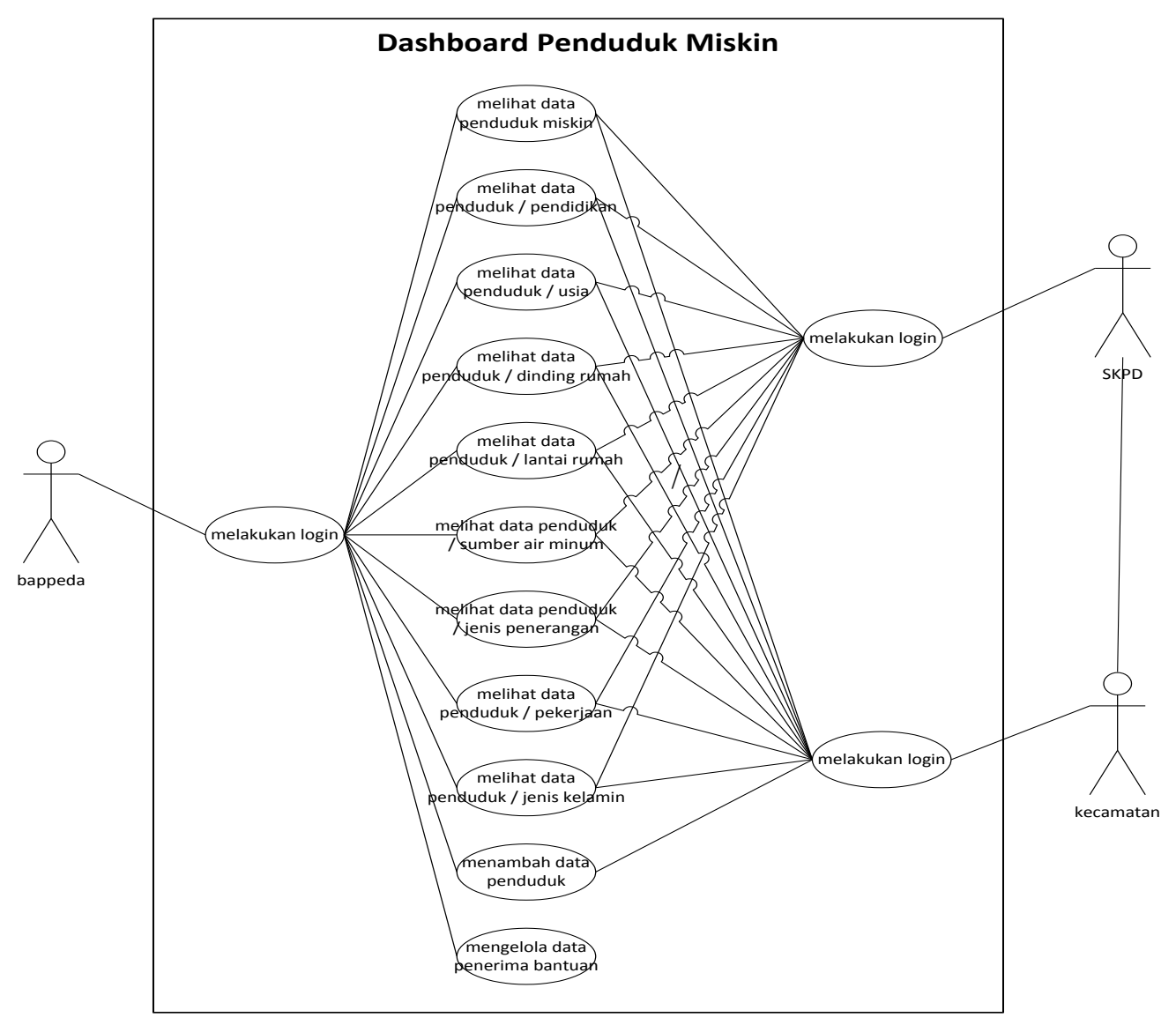

Gambar 3. Use Case Diagram

Bussiness Modeling dibangun berdasarkan struktur organisasi dan kebutuhan pengguna terhadap sistem yang akan dibangun. Dalam hal ini Bappeda merupakan SKPD yang berwenang dalam mengelolah data kemiskinan. Data kemiskinan diambil dari hasil survey BPS. Dari hasil analisis dan pengamatan maka dapat model bisnis digambarkan model bisnis perangkat lunak yang akan dibangun.

1. Pengguna perangkat lunak terdiri dari Bappeda (Badan Perecanaan dan Pembangunan Daerah) yang bertugas sebagai administrator yang betanggung jawab terhadap pengolahan data kemiskinan. Bappeda memiliki wewenang untuk melalakukan perubahan data, mengeolah data penerima bantuan dan informasi /pelaporan data kemiskinan dalam bentuk tabel/grafik.

2. Pengguna yang kedua adalah user kecamatan yang memilik akses untuk melakukan perubahan data kemiskinan serta melihat dan informasi /pelaporan data kemiskinan dalam bentuk tabel/grafik. Hal ini dimaksudkan agar kecamatan memiliki akses langsung terhadap data penduduk miskin yang ada di wilayahnya sehingga data tersebut dapat up to date.

3. Pengguna yang ketiga adalah SKPD yang dapat menggunakan informasi /pelaporan data kemiskinan dalam bentuk tabel/grafik sesuai dengan program pengetasan kemiskinan yang akan dilaksanakan.

\subsection{Data modeling}

Pada tahap ini dilakukan permodelan data yang berasal dari analisis kebutuhan (requirement analisis) yang dilakukan di fase bussiness modeling. Data modeling adalah cara formal untuk menggambarkan data yang digunakan dan diciptakan dalam 
suatu sistem bisnis [1]. Pada tahap data modeling akan dilakukan proses merancang basis data dalam betuk Entity Relationship Diagram (ERD) sampai membuat basis data secara fisik. Terdapat tiga tahapan yang dilakukan dalam perancangan model data/basis data :

1. Perancangan Konseptual

Menterjemahkan skema bisnis yang sudah dilakukan pada fase bussiness modeling ke dalam model ERD (Entity Relational Diagram).

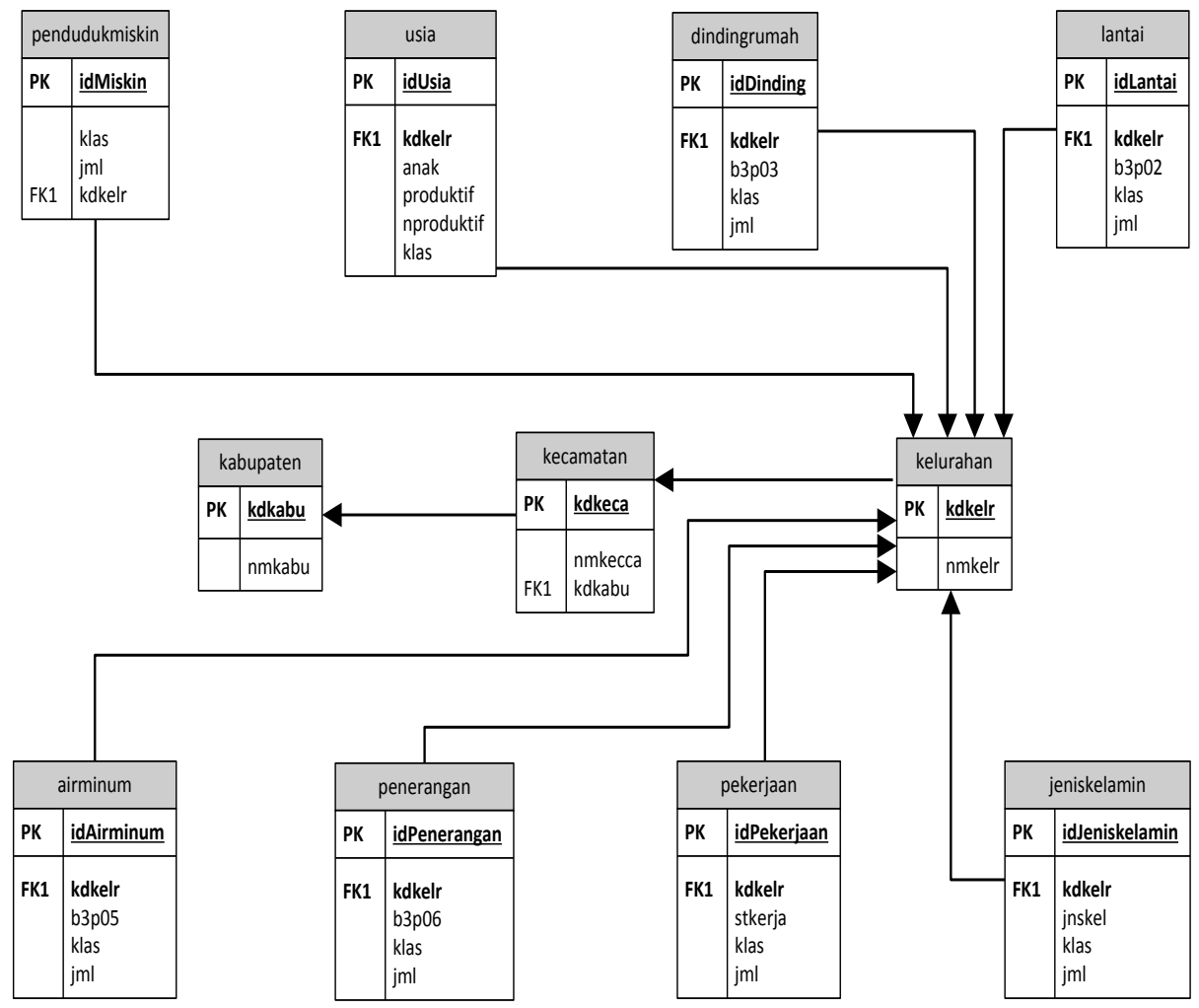

Gambar 4. ER - Diagram

2. Perancangan Logical

Melakukan transformasi dari skema konseptual ke skema logic. Menterjemahkan ERD ke dalam skema database. Berikut rancangan skema database perangkat lunak kemiskinan yang dibangun.

3. Peracangan Phisical

Menterjemahkan skema logic ke dalam skema fisik database dalam sebuah software DBMS (Database Management System). Berikut desain fisik database kemiskinan dalam bahasa SQL - DDL (Data Definition Language).

\subsection{Process Modeling}

Pada tahapan process modeling pekerjaan yang dilakukan adalah membuat alur proses dari perangkat lunak peduduk miskin. Alur proses perangkat lunak dapat digambarkan dalam model activity diagram . Alur proses activity diagram menjelaskan alur proses/interaksi yang terjadi antara user / pengguna dengan sistem. Berikut ini activity diagram untuk proses di level Bappeda : 


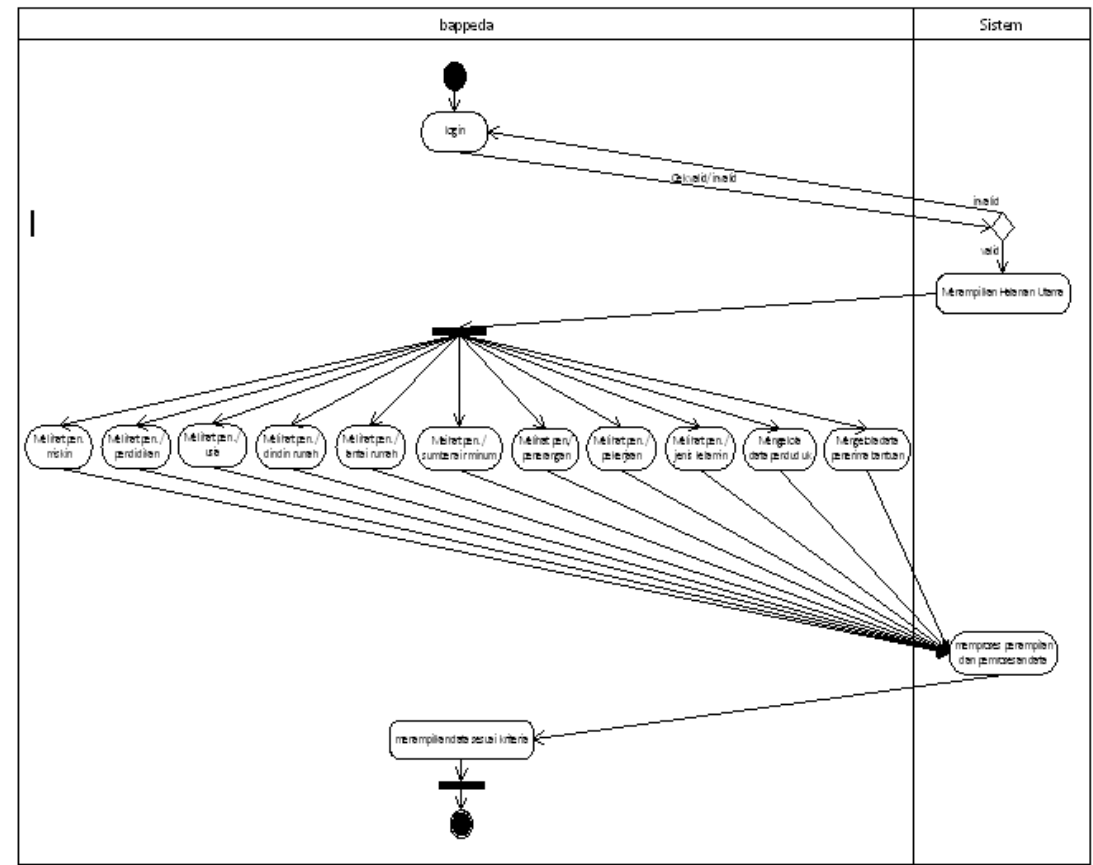

Gambar 4. Activity Diagram

Pada gambar 4 dijelaskan activity diagram yang dilakukan pada level Bappeda. Level ini merupakan level administrator pada model perangkat lunak kemiskinan.

\subsection{Application Gereration}

Tahapan application generation pekerjaan yang dilakukan adalah melakukan pengkodean atau implementasi dari process modeling dan data modeling. Hasil akhir dari tahap ini adalah dihasilkan sebuah perangkat lunak kemiskinan berbasis web yang mampu mengakomodir keperluan Bappeda, Kecamatan dan SKPD terkait terhadap data kemiskinan. Perangkat lunak kemiskinan ini merupakan model perangkat lunak yang diharapkan mampu membantu pihak pemerintah dalam melaksanakan program pengentasan kemiskinan yang sesuai dengan kondisi masyarakat. Informasi yang dihasilkan perangkat lunak menyangkut informasi kondisi masyarakat miskin berdasarkan indikator kemiskinan, usia, pekerjaan, penerangan, air minum dan kondisi tempat perwilayah. 


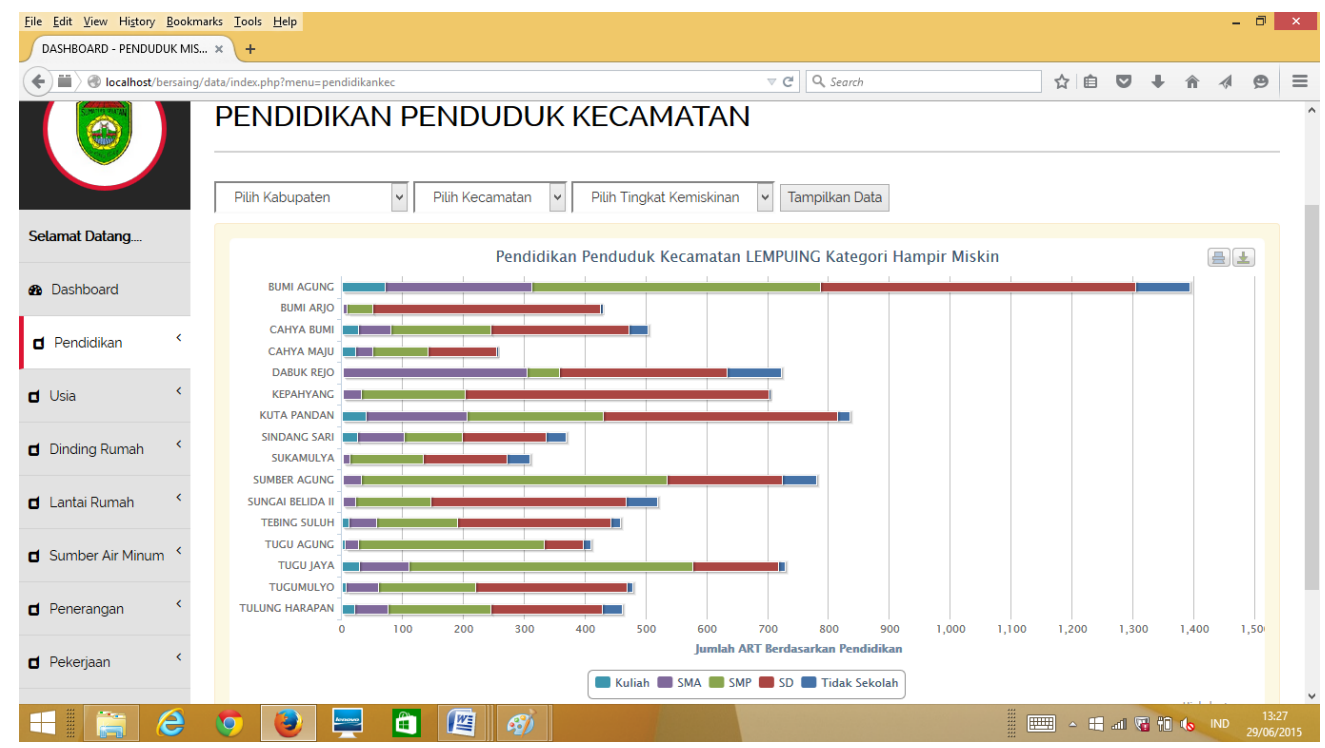

Gambar 5. Dasboard Application

Perangkat lunak informasi kemiskinan mengambil contoh data kemiskinan kabupaten Ogan Komering Ilir di provinsi Sumatera Selatan. Dari gambar 5 diatas, informasi yang disajikan pada perangkat lunak informasi kemiskinan ini dikelompokan berdasarkan pendidikan, usia penduduk, kondisi tempat tinggal (dinding rumah dan lantai rumah), sumber air minum, penerangan, pekerjaan dan gender (jenis kelamin). Pemerintah dapat memanfaatkan informasi yang tersedia pada perangkat lunak ini sebagai alat bantu dalam pencarian informasi yang dibutuhkan untuk penyelenggaraan program pemberantasan kemiskinan yang meliputi bantuan sosial, pemberdayaan masyarakat, pemberdayaan usaha ekonomi mikro dan kecil, serta program lain dalam rangka meningkatkan kegiatan ekonomi kerakyatan yang akhirnya dapat membantu dalam peningkatan kesejateraan masyarakat.

\subsection{Testing and Turnover}

Pada tahapan testing, pekerjaan yang dilakukan adalah melakukan pengujian perangkat lunak penduduk miskin yang telah dibuat. Pengujian tersebut dilakukan perkomponen menggunakan metode black box. yang hanya berfokus pada kebutuhan fungsional perangkat lunak. Pada kasus uji dengan proses yang sama akan diwakilkan oleh satu proses kasus uji. Pengujiannya terdiri dari validation testing dan unit testing. Sebelum melakukan pengujian dilakukan identifikasi hal yang akan diuji dan rencana pengujiannya. Hal ini dilakukan supaya perangkat lunak yang dibuat dapat terukur berdasarkan input yang dimasukan dan output yang diharapkan.

\section{KESIMPULAN}

Berdasarkan hasil penelitian diatas maka dapat disimpulkan sebagai berikut :

1. Perangkat lunak kemiskinan mampu menghasilkan informasi yang dibutuhkan oleh pemerintah dan pihak terkait yang membutuhkan informasi data kemiskinan terkait pelaksanaan program pengentasan kemiskinan.

2. Menjadi sebuah media informasi yang dapat mewujutkan transparansi informasi mengenai data penduduk miskin dan indikator kemiskinan penduduk miskin dari suatu wilayah kabupaten/kecamatan. 


\section{DAFTAR PUSTAKA}

[1] Al Fatta, Hanif, 2007, Analisis dan Perancangan Sistem Informasi untuk Keunggulan Perusahaan dan Organisasi, Penerbit Andi - STMIK Amikom, Yogyakarta.

[2] Noname, 2010, Peraturan Menteri Dalam Negeri Nomor 42 Tahun 2010 Tentang Tim Koordinasi Penanggulangan Kemiskinan Provinsi Dan Kabupaten/Kota, Kemendagri

[3] Setiawan, Ade, 2011, Rapid Application Development. Univesitas Gunadarma

[4] Therling K, 2006, An Introduction to DataMining: Discovering hidden value in your data warehouse, www.thearling.com, diakses tanggal 2 April 2013

[5] Whitten L Jeffery, Bentley D. Lonnie, Dittman C. Kevin, 2004, Metode Desain dan Analisis Sistem, Edisi 6., Edisi Internasional Mc.Graw Hill Education dan Penerbit Andi Jogyakarta 